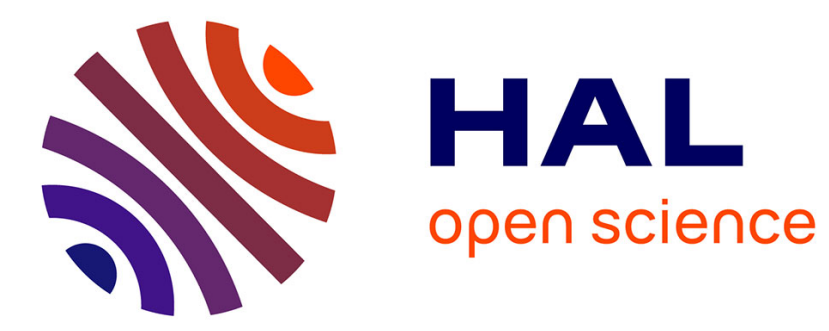

\title{
Structural study of calcium phosphate ceramics by convergent beam electron diffraction (CBED)
}

\author{
E. Brès, R. Vincent, J.-P. Morniroli, G. Pourroy
}

\section{To cite this version:}

E. Brès, R. Vincent, J.-P. Morniroli, G. Pourroy. Structural study of calcium phosphate ceramics by convergent beam electron diffraction (CBED). Journal de Physique IV Proceedings, 1993, 03 (C7), pp.C7-1435-C7-1438. 10.1051/jp4:19937222 . jpa-00251858

\section{HAL Id: jpa-00251858 https://hal.science/jpa-00251858}

Submitted on 1 Jan 1993

HAL is a multi-disciplinary open access archive for the deposit and dissemination of scientific research documents, whether they are published or not. The documents may come from teaching and research institutions in France or abroad, or from public or private research centers.
L'archive ouverte pluridisciplinaire HAL, est destinée au dépôt et à la diffusion de documents scientifiques de niveau recherche, publiés ou non, émanant des établissements d'enseignement et de recherche français ou étrangers, des laboratoires publics ou privés. 


\title{
Structural study of calcium phosphate ceramics by convergent beam electron diffraction (CBED)
}

\author{
E.F. BRÈS $(1)$, R. VINCENT ${ }^{*}$, J.-P. MORNIROLI ${ }^{* *}$ and G. POURROY ${ }^{* * *}$
}

Max-Planck Institut für Metallforschung, Institut für Werkstoffwissenschaft, Seestrasse 92, 7000 Stuttgart 1, Germany

${ }^{*}$ H.H. Wills Physics Laboratory, University of Bristol, Bristol, U.K.

** Laboratoire de Métallurgie Physique, URA 234 du CNRS, Université de Lille I, Lille, France

${ }^{* * *}$ IPCMS-GMI, Université Louis Pasteur, Strasbourg, France

\section{STRUCTURAL STUDY OF CALCIUM PHOSPHATE CERAMICS BY CONVERGENT BEAM ELECTRON DIFFRACTION (CBED)}

\begin{abstract}
E. F. Brès ${ }^{1}$, R. Vincent ${ }^{2}$, J.-P. Morniroli ${ }^{3}$ and G. Pourroy ${ }^{4}$.
1Max-Planck Institut für Metallforschung, Institut für Werkstoffwissenschaft, Seestrasse 92, D 7000 Stuttgart 1, Germany. On leave from the "Laboratoire de Recherche sur les Tissus Calcifiés et les Biomatériaux", Faculté de Chirurgie Dentaire, place Alexis Ricordeau, 44042 Nantes Cedex 01, France. ${ }^{2}$ H. H. Wills Physics Laboratory, University of Bristol, Bristol, UK. ${ }^{3}$ Laboratoire de Métallurgie Physique (URA CNRS 234), Université de Lille I, France.4IPCMS-GMI, Université Louis Pasteur, Strasbourg, France.
\end{abstract}

\section{INTRODUCTION}

Calcium phosphate ceramics are widely used for the fabrication of prosthetic implants. Calcium phosphate biomaterials either consist of sintered compacts or are deposited on metal shafts such as commercially pure $\mathrm{Ti}$ or $\mathrm{Ti}$ alloys by, for example, plasma spraying. The mechanical properties and the in vivo behaviour of calcium phosphate materials are highly dependent on factors such as: $\mathrm{Ca} / \mathrm{P}$ ratio, crystallographic structure, porosity, etc. Hence, the identification of the resulting phases produced after sintering or plasma deposition is a very important process. However, the identification of the different calcium phosphate phases by the measurement of their $\mathrm{Ca} / \mathrm{P}$ ratio using the EDS or EELS electron microscopy techniques is difficult because the $\mathrm{Ca}^{2+}$ ions are selectively ejected by the electron beam during the observation of the sample so that the measured $\mathrm{Ca} / \mathrm{P}$ ratios measured are lower than real ratiosthe with respect to the nominal ratios [1]. One way to identify the phase of separate calcium phosphate grains within a compact is to determine their space group. However, the space groups of several calcium phosphate phases have not yet been determined. For example, it is not yet known if $B$ tricalcium phosphate $\left(B T C P, \mathrm{Ca}_{3}\left(\mathrm{PO}_{4}\right)_{2}, \mathrm{Ca} / \mathrm{P}=1.5\right.$ ) possesses an inversion centre and so two space groups are possible: $R \overline{3} c$ (whitlockite) [2] or the $R 3 c$ [3]. Consequently, in this presentation, the determination by CBED of the full space group of several calcium phosphate phases (synthetic hydroxyapatite (OHAP, $\left.\mathrm{Ca}_{10}\left(\mathrm{PO}_{4}\right)_{6}(\mathrm{OH})_{2}, \mathrm{Ca} / \mathrm{P}=1.67\right)$, $\mathrm{B}$-tricalcium phosphate...) is outlined. 


\section{MATERIALS AND METHODS}

The powders were prepared by.the following reactions: 1 ) $\mathrm{OHAP}: 3 \mathrm{Ca}_{3}\left(\mathrm{PO}_{4}\right)_{2}+2 \mathrm{Ca}(\mathrm{OH})_{2 .->}$ $\mathrm{Ca}_{10}\left(\mathrm{PO}_{4}\right)_{6}(\mathrm{OH})_{2}$ at temperatures from 900 to $1200^{\circ} \mathrm{C}$ and 2) $\mathrm{BTCP} \mathrm{CaCl}_{2}$.in alcohol $+\mathrm{H}_{3} \mathrm{PO}_{4}->$ $\mathrm{Ca}_{3}\left(\mathrm{PO}_{4}\right)_{2}$ after drying at $800 \mathrm{C}^{\circ}$. The CBED patterns were produced with a JEOL 2000FX (Stuttgart) and a Philips EM430 (Bristol).

\section{RESULTS}

\section{OHAP}

Reflections in the zero layer of the [0001] CBED pattern of OHAP are arranged in a triangular net indicating a $\mathrm{P}$ Bravais lattice (Fig. 1). This is confirmed by the relative displacement of $1 / 2 a^{*}$ observed between zero-order and first-order nets of reflections in $<1120>$ patterns (Fig. 3). A six fold projection symmetry of the zero-layer reflections in the zero-layer with clear abscence of mirror parallel to the $c$ axis indicates a $6 / \mathrm{m}$ point group, with four possible space groups: $P 6, P 6_{3}, P 6 / \mathrm{m}$ or $P 6_{3} / \mathrm{m}$. The existence of a mirror plane in the first order Laue zone pattern of the $<1120>$ axis (Fig.3) leaves us two possibilities: $P 6 / \mathrm{m}$ and $P \sigma_{3} / \mathrm{m}$. Finally, dynamical extinctions in the $000 l$ ( $l$ odd) reflections (Fig. 2) indicate the presence of a screw axis within the OHAP structure and leads us to the $P \sigma_{3} / \mathrm{m}$. space group for OHAP.

\section{BTCP}

The space group of BTCP can be determined by a single CBED pattern (Fig. 4). $3 m$ symmetries in both zero-order and first-order nets of reflections (Fig. 4) correspond either to the $\langle 111\rangle$ direction of the $43 \mathrm{~m}$ cubic point group or to the [0001] direction of the $3 \mathrm{~m}$ trigonal point group. But, the cubic Bravais lattices $(\mathrm{P}, \mathrm{I}, \mathrm{F})$ are excluded by the three-dimensional geometry of the pattern, $i$. $e$. the first order Laue zone radius relative to the zero layer basis vectors. The abscence of the $P$ Bravais lattice is further confirmed by the position of the zero-order with respect to the first-order reflections, this leads to the $\mathrm{R}$ Bravais lattice. Finally, dynamical extinctions in the first order pattern (see arrows) show the existence of a $c$ glide plane, the space group of BTCP is then $R 3 c$.

\section{CONCLUSION}

In the present study, the full space groups of two stoichiometric calcium phosphates (OHAP and BTCP) have been determined. Because of the small probe size (less than $10 \mathrm{~nm}$ ) and of the inherent sensitivity of the CBED technique to symmetry variations several ambiguities have been solved i.e. the possibilitity of a pseudo hexagonal space group of OHAP or the $R \overline{3} c$ space group of BTCP. In the future other calcium phosphate phases and the possible symmetry variations induced by stoichiometric differences will be investigated.

\section{REFERENCES}

1) SENGER B., BRES, E. F. , HUTCHISON, J. L., VOEGEL, J.-C. and FRANK, R. M. , Phil. Mag.

A. $\underline{65},(1992), 665$.

2) FRONDEL, C., Amer. Min., 26, (1941), 145.

3) DICKENS, B.,SCHROEDER, L. W. and BROWN, W. E., J. Solid State Chem., 10, (1974), 232. 

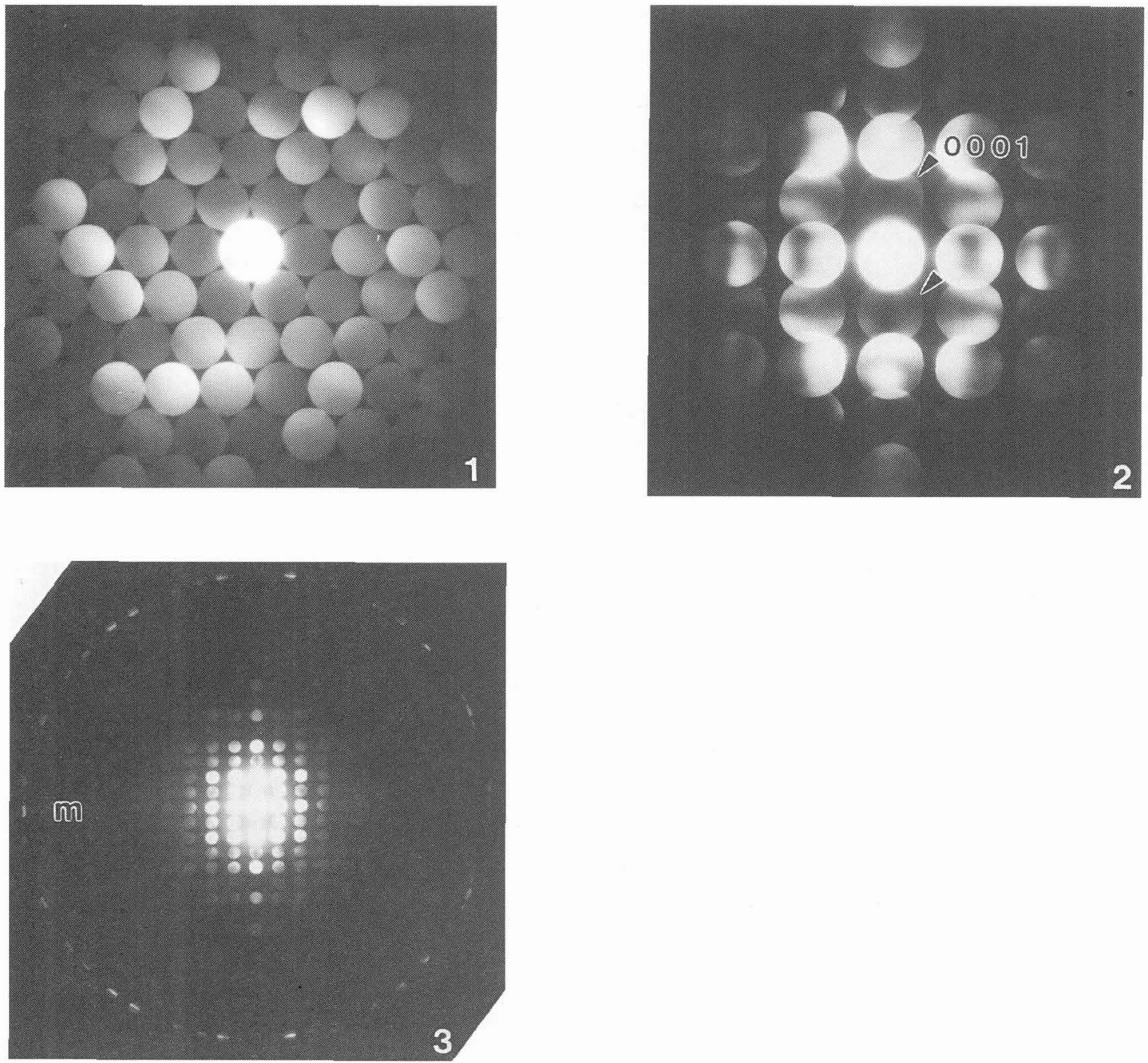

Figure 1: Zero order laue zone CBED pattern of an OHAP crystal aligned along the [0001] zone axis. Figure 2: Zero order laue zone CBED pattern of an OHAP crystal aligned along the $\langle 1120\rangle$ zone axis. Figure 3: Zero and first order laue zones CBED pattern of an OHAP crystal aligned along the $<11 \overline{20}\rangle$ zone axis. 


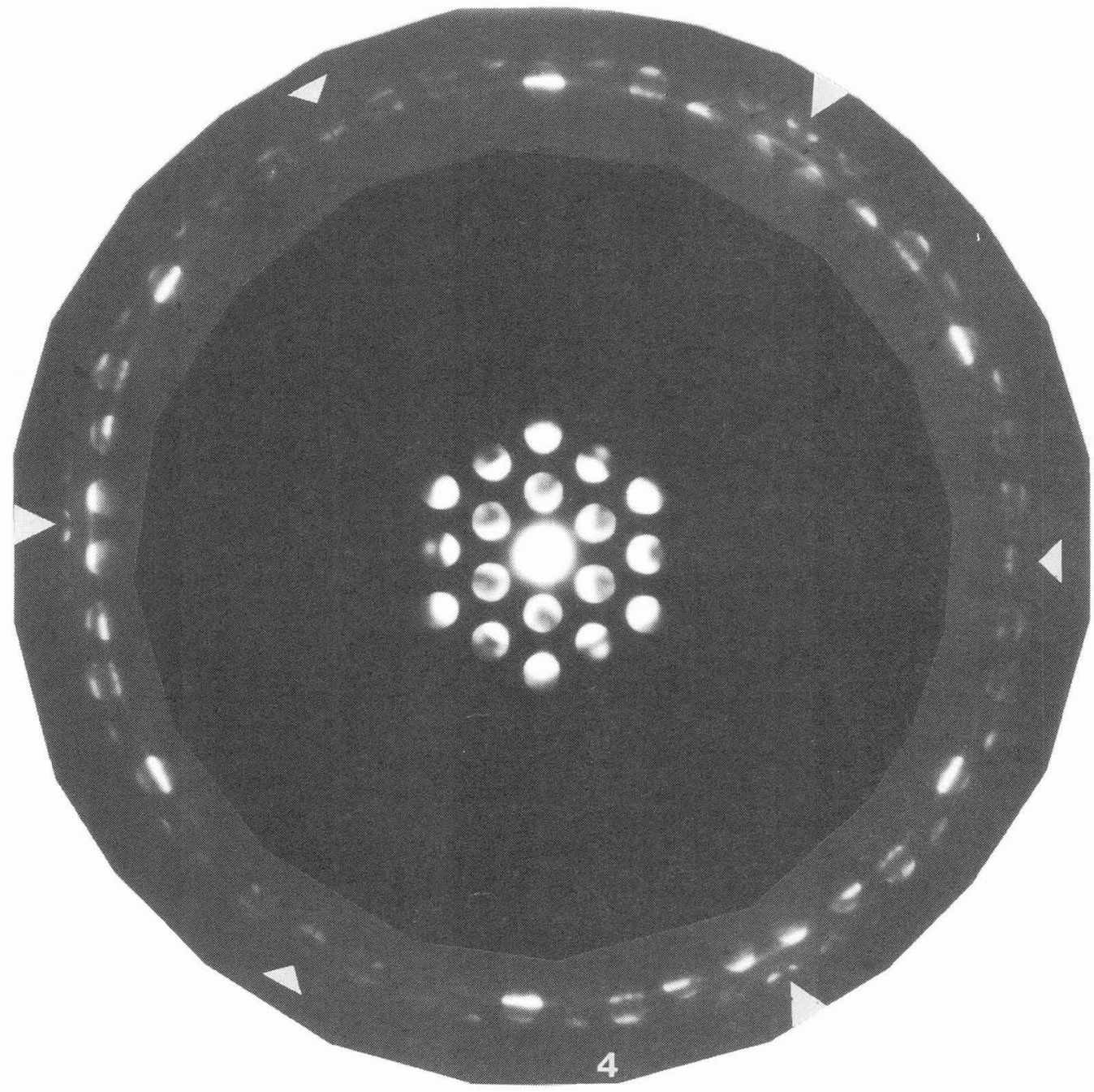

Figure 4: Zero and first order laue zones CBED pattern of a BTCP crystal aligned along the [0001] zone axis. 